\title{
Preconceito e esportes de aventura: A (não) presença feminina
}

\author{
Adventure sports and prejudice: The (no) female presence
}

\author{
G.M. Schwartz, J.P. Figueiredo, L.M. Pereira, D.A. Christofoletti, V.K. Dias
}

ARTIGO ORIGINAL | ORIGINAL ARTICLE

\begin{abstract}
RESUMO
Os esportes de aventura apresentam uma demanda em crescimento na atualidade, tendo em vista suas características envolvendo inúmeros apelos emocionais persuasivos e atraentes. Apesar dessa ascensão, o envolvimento das mulheres nessas atividades ainda se dá de forma restrita, especialmente devido a resquícios de estigmas e preconceitos socialmente arraigados. Entretanto, algumas iniciativas femininas buscam ampliar a participação em diversas modalidades de esporte de aventura. Na literatura há uma lacuna referente aos estudos sobre esportes de aventura, especialmente associado às questões de gênero, preconceito e a atuação de profissionais neste segmento. Estes aspectos mobilizaram este estudo, o qual objetivou investigar a aceitação, por parte dos homens, bem como, possíveis atitudes e condutas preconceituosas, no que tange à presença feminina nos esportes de aventura, no olhar das atletas. O estudo qualitativo constou de pesquisa exploratória, desenvolvida por meio de questionário aberto, aplicado via internet, diretamente nos sites e blogs de 16 atletas brasileiras, com reconhecimento em diferentes modalidades de esportes de aventura. Os dados foram analisados com base na Técnica de Análise de Conteúdo Temático e indicam que, apesar da maioria das atletas não se reportar a preconceitos e à não aceitação dos homens diretamente, estes aparecem subliminarmente, merecendo atenção em novos estudos.

Palavras-chave: preconceito, aventura, esporte
\end{abstract}

ABSTRACT

Participation in adventure sports have increased recently, perhaps because of its appealing and emotional aspects. Despite this overall increase, women's participation is restricted due to ingrained gender prejudice in society, however, there are some initiatives aimed at expanding women's participation in several adventure sports. In scientific literature there is a lack of studies on adventure sports, especially on gender issues, prejudice and female athletic performance. These aspects motivated this study, which aims to investigate from the female athletes' perspective; the prejudice and behaviors of male athletes when in their presence and the male athletes' acceptance of them. This exploratory research consists of a qualitative study developed through an open on-line questionnaire. This tool was posted on web logs and websites of sixteen well-known female Brazilian adventure sports athletes. The questionnaire answers were analyzed based on the Thematic Content Analysis Technique and indicate that, although most female athletes do not report the prejudice and rejection of men, these attitudes appear subliminally, deserving more attention in future studies.

Keywords: prejudice, adventure, sport

Submetido: 16.02.2012 | Aceite: 04.01.2013

Gisele Maria Schwartz, Juliana de Paula Figueiredo, Leonardo Madeira Pereira, Danielle Ferreira Auriemo Christofoletti, Viviane Kawano Dias. Instituto de Biociências,UNESP-RC - Universidade Estadual Paulista "Júlio de Mesquita Filho" campus de Rio Claro, Brasil.

Endereço para correspondência: Gisele Maria Schwartz, Laboratório de Estudos do Lazer - LEL / Departamento de Educação Física - DEF/ Instituto de Biociências - IB/ Universidade Estadual Paulista "Julio de Mesquita Filho” - UNESP / Campus de Rio Claro. Avenida 24A, n 1515, Bela Vista, Rio Claro, São Paulo,Brasil. CEP: 13506-900, Brasil.

E-mail: schwartz@rc.unesp.br 
As atividades de aventura e o turismo de aventura representam um nicho de mercado de bastante sucesso, dentro das opções relacionadas ao entretenimento e ao lazer na atualidade. Derivadas desta perspectiva foram criadas determinadas sistematizações que levaram ao surgimento de algumas modalidades de esportes de aventura. Estas atividades possuem características bastante atraentes e persuasivas, voltadas, especialmente, ao contato com a instabilidade do ambiente natural e com experimentações baseadas em risco controlado, o que pode propiciar sensações inusitadas, assim como fortes emoções.

Os esportes de aventura costumam atrair a atenção de atletas arrojados e ávidos por pertencerem a um seleto grupo de aventureiros, que parecem se deslumbrar com a representação do mito do herói e da eterna juventude, associado ao imaginário dessas técnicas. Porém, suas reais características são ainda praticamente desconhecidas, tendo em vista a carência de reflexões a respeito dessas modalidades. No âmbito da Psicologia do Esporte, poucos estudos já foram efetivados, no sentido, principalmente, de se conhecer os motivos de adesão a estas práticas. Entretanto, no que tange às características psicofisiológicas, muito ainda se tem que investigar. Talvez, uma das razões para esta falta de atenção da academia para com estes esportes tenha relação com a dificuldade de atuação e de coleta de dados em um setting altamente diferenciado (ambiente natural), contendo inúmeras variáveis de difícil controle.

O esporte de aventura e os atletas já são uma realidade, merecendo o olhar da academia sobre os inúmeros parâmetros ainda a serem investigados neste contexto. Um dos pontos que chamam a atenção, quando o foco recai nos esportes de aventura, é a questão da diferenciação de gênero. Conquanto algumas modalidades de esportes de aventura já recebam o público feminino de modo mais natural, especialmente devido aos ditames de regras próprias para a composição de equipes, como é o caso da corrida de aventura, para que este público se insira no âmbito de outras modalidades, parece ainda haver uma série de quesitos, os quais, não raro, dificultam esse acesso.

Quando se analisam diretamente os esportes de aventura, pode-se constatar a escassez de mulheres envolvidas, o que revigora a tese de que ainda se percebem inúmeros equívocos e limitações preconceituosas, que se contrapõem como barreiras impeditivas para a vivência feminina nessas atividades. Essas barreiras de caráter estigmatizante podem promover o desrespeito às mulheres que, porventura, não tenham um perfil técnico desenvolvido, ou sendo consideradas como incompetentes para essas atividades esportivas, somente levando-se em consideração valores socioculturais retrógrados.

Estes aspectos referentes à questão de preconceito e gênero e da carência de mulheres envolvidas nos esportes de aventura, representaram a inquietação geradora deste estudo. Sendo assim, torna-se relevante buscar analisar esse universo temático, no sentido de se compreender melhor como se dá a inserção da mulher nas atividades e esportes de aventura na atualidade.

Algumas mulheres já ultrapassaram certas barreiras e desafios culturais e se impuseram no ambiente do esporte de aventura, tornando-se atletas de diferentes modalidades. Portanto, este facto se torna bastante instigante, no sentido de se compreender, no olhar dessas atletas, como se efetivam as relações de gênero no contexto dos esportes de aventura.

Sendo assim, este trabalho teve por objetivo investigar a aceitação, por parte dos homens, bem como, possíveis atitudes e condutas preconceituosas, no que tange à presença feminina nos esportes de aventura, no olhar de atletas já consagradas no âmbito dos esportes de aventura no Brasil.

\section{Revisão de literatura}

A luta feminina pela igualdade de direitos 
e oportunidades sociais não é nova e alguns autores salientam que esta percepção de desigualdade se dá em diversos contextos culturais (Rutland, Killen, \& Abrams, 2010). No campo do esporte, esta desigualdade é bastante patente, o que mereceu a atenção de inúmeros estudiosos (Oliveira, Cherem, \& Tubino, 2008; Valporto, 2006), preocupados em compreender as relações de poder e gênero envolvidas, no âmbito esportivo.

Nas reflexões promovidas por Gill e Kamphoff (2010), os autores afirmam que a categoria de gênero está envolvida em diferentes âmbitos da sociedade, inclusive, no que concerne ao contexto esportivo. Esses autores também salientam que as perspectivas de foco sobre o feminismo e o multiculturalismo representam, ainda, fatores que merecem atenção da área acadêmica. Estas discussões são imprescindíveis, no sentido de favorecer a desconstrução da hipérbole relativa à supremacia masculina associada ao mundo do esporte, em busca da justiça de gênero e de suplantar as lacunas impregnadas na realidade social, reconhecendo-se a importância do papel feminino nessa nova construção do esporte contemporâneo (Vertinsky, 2010).

A desigualdade de gênero associada ao campo do esporte parece exceder as quadras e pistas, entrando, agora, na perspectiva das atividades e esportes de aventura. A mulher, para conseguir suplantar o preconceito arraigado sobre sua presença nas atividades de aventura, enfrenta diversas barreiras. Entre elas, podem-se notar as representações sociais de gênero.

$\mathrm{O}$ papel feminino sempre foi associado à fraqueza e aos detalhes estéticos, entre outras características adotadas para a mulher como um valor aceito em sociedade (Lippa, 2010; Romariz, Devide, \& Votre, 2007). Sendo assim, fica difícil suplantar o pressuposto de que as mulheres são muito femininas para viverem se machucando, marcando a pele, ou, o que é pior, a consideração de que são incompetentes para tais atividades. Como afirma Goellner (2003), para a mulher, parecem ser prerrogativas sociais apenas os atributos de ser bela, feminina e maternal, desconsiderando-se, ainda, toda a sua potencialidade em outros papéis assumidos.

Ampliando-se o foco para os esportes de modo geral, pode-se perceber a falta de reconhecimento dado à figura feminina, ilustrado na dificuldade que estas possuem para galgar cargos deliberativos nas federações esportivas, ou, de terem credibilidade para arbitrarem ou dirigirem como técnicas algumas atividades esportivas, ou mesmo, de receberem patrocínio como atletas, em relação aos homens. Outra barreira existente é a supremacia da massificação da figura masculina no esporte, em detrimento da figura feminina (Goellner, 2005). Isto se pode notar, inclusive, na esfera de propaganda e venda de marcas, em que os homens são também mais visados.

Estas representações sobre a figura do homem ligada ao esporte têm estreita relação com o mito do herói, cuja designação imaginária o coloca como portador de poderes intensos, capazes de superar qualquer obstáculo (Costa, 2000; Costa \& Tubino, 1999). O imaginário relativo à força, potência e virilidade está diretamente associado ao corpo masculino, pensamento que rechaça a força, a potência e a garra da mulher atleta (Cheung \& Halpern, 2010).

Ao se fazer uma incursão pelas publicações referentes às atividades e esportes de aventura, pode-se notar que poucos trabalhos estão divulgados focalizando a figura feminina atuante nesses esportes. Alguns livros já publicados (Gasques, 2002; Ortiz, 2007) reiteram a luta feminina por estratégias capazes de inseri-las e serem reconhecidas no âmbito dos esportes de aventura.

Entretanto, pode-se perceber que diversos desses livros, basicamente escritos por homens, fazem apenas alguma menção sobre a presença feminina no esporte de aventura. Quando citadas, estas figuras femininas se mostram em fotos, apenas ilustrando a pessoa de alguém 
famosa ou a foto de uma medalha conquistada, não havendo registros de mulheres fazendo manobras ousadas ou em ação efetiva na modalidade (Figueira, 2008).

Ao se atentar o olhar para a divulgação sobre os esportes e atividades de aventura em diferentes mídias, pode-se perceber, também, a predominância de reportagens sobre atletas masculinos, em relação às atletas femininas. Estas, quando são focalizadas pela mídia televisiva, por exemplo, aparecem apenas para reforçar a beleza, a feminilidade e a vaidade, mas, raramente, são expostas mostrando suas habilidades técnicas, sua competência estratégica na atividade, ou sua coragem e radicalidade em determinado lance ou tarefa motora, como já apontou Figueira (2008).

Ainda sobre essa forma preconceituosa de apreensão do universo feminino pelas mídias, pode-se perceber a insistência dos canais televisivos em buscar termos como deusas, ninfas, musas, para definirem as mulheres atletas em ação. Esta posição reforça a ideia de algo fora do normal ou diferente, já que, com esta visão, as mulheres atuantes nesses esportes parecem ser tomadas como seres irreais (Figueira, 2008), ou, apenas desta forma, se igualar aos feitos dos homens.

Como estratégias de disseminação do trabalho feminino com o esporte de aventura, a criação de associações esportivas femininas já é uma realidade para algumas atividades de aventura, como no caso do skate. $\mathrm{Na}$ mídia impressa, também já se notam algumas iniciativas, como entrevistas e reportagens em revistas, descrevendo os processos da atividade, ou comentando-se sobre alguma participação em campeonato. Porém, tudo isto ainda é bastante pouco.

Ainda que estas iniciativas já estejam em curso, são muitas as barreiras que a mulher terá que enfrentar, para conseguir se impor como atleta nos esportes de aventura e superar a desigualdade de gênero. Quando se procura investigar, inclusive, a presença de profissionais do sexo feminino envolvidos com os treinamentos técnicos, tático e psicológico nos esportes de aventura, nota-se também uma ausência de enfoques na literatura específica, sobre estas temáticas. Sendo assim, tornam-se prementes novos olhares sobre esses e outros enfoques no campo dos esportes de aventura, no sentido de se contribuir para as futuras reflexões e se promover a tão almejada mudança axiológica em prol da valorização feminina nos esportes de aventura.

\section{MÉTODO}

\section{Amostra e Instrumentos}

Este estudo teve uma natureza qualitativa, em função de que esta, conforme salienta Richardson (1999), possibilita uma melhor compreensão do universo pesquisado, captando, de forma mais intensa e aprofundada, os fenômenos e mudanças inseridos num contexto social. Para tanto, o estudo foi desenvolvido em duas etapas, sendo a primeira referente a uma revisão de literatura sobre as temáticas propostas e pertinentes ao entendimento deste estudo, e a segunda a uma pesquisa exploratória, a qual permitiu entrar no universo da população a ser analisada de forma direta, favorecendo o conhecimento real da situação e a identificação de problemas e possíveis soluções.

A pesquisa exploratória utilizou como instrumento para a coleta dos dados um questionário contendo perguntas abertas e aplicado online. A aplicação do instrumento de coleta de dados online, utilizando, assim, a informática, apresenta pontos positivos, como destaca Joly e Silveira (2003), por agilizar a coleta dos dados, favorecer o acesso aos sujeitos, além de tornar a análise mais ágil, contribuindo, ainda, no aspecto econômico, possibilitando segurança e interação com o sujeito da pesquisa de maneira mais rápida.

A amostra intencional participante do estudo foi constituída por 16 mulheres, com faixa etária entre 24 a 51 anos, totalizando uma 
média de 34 anos, selecionadas pelo facto de serem praticantes de atividades de aventura na natureza há algum tempo, sendo atletas de nível nacional no Brasil. Dessas atletas, 15 possuíam nível de escolaridade superior completo e apenas uma o segundo grau incompleto. Dentre os tipos de atividades praticadas, estas atletas citaram estarem envolvidas em diversas modalidades, entre elas: escalada, montanhismo, mountain bike, rafting, skate, corrida de orientação, canoagem, trekking, ciclismo, rappel, pára-quedismo, bóia-cross, canyoning e balonismo. No que concerne ao tempo de prática dessas atividades, este variou entre dois e 29 anos, obtendo-se uma média de 9.5 anos.

\section{Procedimentos}

O estudo foi aceito pelo Comitê de Ética em Pesquisa com Seres Humanos do Instituto de Biociências, da UNESP, campus de Rio Claro/ SP/Brasil, sob protocolo número 06313. Inicialmente, foi realizada uma pesquisa exploratória em redes sociais da internet, blogs e sites, nos quais foram identificadas algumas atletas que se destacavam no cenário nacional e/ou internacional de esportes de aventura, momento em que foi realizado o convite para participação na pesquisa, bem como, a explicação dos objetivos do estudo, assegurando a garantia do anonimato e solicitado a estas o e-mail para contato. Desta maneira, foi repassada a versão do questionário a ser respondido. De posse da anuência das atletas, estas procederam à assinatura digital do Termo de Consentimento Livre e Esclarecido e às respostas ao questionário.

Os dados coletados por meio da aplicação do instrumento foram analisados de forma descritiva, utilizando-se a Técnica de Análise de Conteúdo Temático. Esta técnica, conforme Richardson (1999), permite evidenciar os aspectos mais relevantes do contexto das respostas e que mais diretamente respaldam o objetivo proposto no estudo.

\section{RESULTADOS E DISCUSSÃO}

A questão 01 do questionário relacionou-se aos aspectos motivacionais que provocaram a aderência dessas mulheres aos esportes de aventura. O principal motivo citado foi a identificação com este tipo de atividade, para seis atletas, seguido da perspectiva de poder estar em contato direto com o ambiente natural, motivo citado por cinco atletas; duas apontaram a palavra adrenalina como motivo; as sensações de prazer, bem-estar e satisfação foram citadas por três atletas, sendo uma para cada um desses motivos.

Entre os estudiosos dos esportes e atividades de aventura no Brasil (Bruhns, 2009; Dias \& Alves Junior, 2009; Marinho, 2008; Tahara, Carnicelli Filho, \& Schwartz, 2006; Tahara, 2004), o gosto pela atividade ao ar livre e a perspectiva de alcance de prazer são os motivos mais frequentemente atribuídos à adesão a estas práticas. Para Bruhns (2009), as atividades realizadas em ambientes naturais fazem restabelecer uma relação mais efetiva entre o ser humano e a natureza, avivando, de modo mais intenso, essa associação. Em outros estudos, como o de Gomes e Isayama (2009), esta relação humana com o ambiente natural e o prazer são os fatores motivacionais mais relevantes.

Nos estudos de Lavoura, Schwartz, e Machado (2008), a possibilidade de vivência de emoções diferentes daquelas advindas das experiências cotidianas, é um forte motivo de adesão, também citado nesse presente estudo, quando as atletas apontam o prazer, bem-estar e adrenalina. $\mathrm{O}$ facto de as atletas citarem algumas emoções que estão fortemente presentes nessas atividades, também corrobora com estudos anteriores (Paixão, 2010; Lavoura, Schwartz, \& Machado, 2008; Schwartz, 2002).

Com base nestes autores, foi possível observar uma grande incidência de estudos que apontam os aspectos emocionais como expressivo motivo de aderência a essas atividades. Embora no presente trabalho as parti- 
cipantes também tenham citado as sensações e emoções como fator desencadeador de inserção nas atividades de aventura, vale ressaltar que a identificação com este tipo de atividade e o contato com o ambiente natural é que foram os elementos mais destacados.

No que se refere à valorização das características das atividades de aventura, Betrán (2003, p. 159) aponta que há um "mix atrativo", formado pelos elementos natureza, esporte, aventura, relacionamentos, dentre outros, os quais instigam as pessoas a procurarem e aderirem à essas atividades. Quanto ao contato com a natureza, Amaral e Dias (2008) também apresentam que este é o motivo primordial citado pelos participantes em sua pesquisa, salientando que os indivíduos buscam, por meio dessas atividades, a harmonia com o ambiente natural, o equilíbrio, a interação e o reencontro com a natureza, corroborando, assim, os dados encontrados neste trabalho.

Em outros estudos, como os de Silva e Freitas (2010) e de Bahia e Sampaio (2007), os principais motivos não se coadunam com estes apontados no presente estudo, uma vez que os autores ressaltam a possibilidade de condutas compensatórias ao se procurar as atividades em contato com a natureza, tanto em relação às vivências diferenciadas, como no que concerne ao facto de os adeptos desvelarem sentidos camuflados em seus íntimos. De todo modo, esses fatores não deixam de estar relacionados aos aspectos das emoções, porém, isto reforça a necessidade de novos estudos, devido à complexidade desses fenômenos.

Estes aspectos subjetivos são persuasivos, tanto do ponto de vista das atividades, quanto das atletas em si mesmo. Esta afirmação se baseia no facto de que bem pouco se tem voltado a atenção para se entender esse paradoxo envolvendo diretamente as atividades de aventura e sua característica atrativa de favorecer o prazer de sentir medo, seja este imaginário ou real. Talvez, este elemento esteja diretamente associado a algum traço de perso- nalidade, capaz de auferir a confiança necessária para o enfrentamento da situação-problema, de modo a alcançar o prazer de vencer obstáculos.

Em relação à questão de número 02 , referente a sentir ou não algum tipo de preconceito, nove das participantes declararam não perceberem qualquer tipo de preconceito, apoiando suas justificativas sobre o facto, principalmente, de serem consideradas peças-chave em alguns esportes, como na corrida de orientação. Para esta atividade, a presença feminina é exigida, o que, de certa forma, conduz ao facto de não haver desvalorização quanto à inserção da mulher nesta modalidade esportiva. Algumas também se reportaram ao facto de receberem incentivo e apoio dos homens, quando estão nos grupos de prática, o que, para elas, representaria a ideia aventada de não sentirem preconceito.

Quando se trata do universo dos esportes, é possível observar que mesmo hoje alguns estereótipos de gênero não foram extintos, sendo visíveis em modalidades que mantêm a distinção de atributos pertencentes ao grupo masculino e ao grupo feminino. Saraiva (2009) discorre sobre tal assunto reforçando o facto de que a educação física contribuiu bastante para a masculinização do esporte e uma feminilização das atividades rítmico-expressivas. Cabe ainda ressaltar que pesquisas de gênero e estudos que discutem questões relativas ao corpo feminino têm sido capazes de esclarecer o motivo que gera tais desigualdades (Devide, 2003; Goellner, 2003). Entretanto, também ficou patente que sete participantes apontaram sentir preconceito nessas práticas. Suas justificativas recaem no facto de que esse preconceito não é apenas restrito aos homens participantes destes esportes, mas é advindo da própria sociedade, já que estas atividades ainda são vistas como estritamente masculinas. É importante ressaltar que esta participação feminina só tornou-se mais evidente no começo do século $\mathrm{XX}$, no qual ocorreram algumas modificações das idéias e representações sobre o corpo femi- 
nino e quando havia o apoio e incentivo da família (Mourão, 1998; Goellner, 2003).

Algumas respostas também evidenciaram sutis ou subliminares elementos preconceituosos, já que foi citado que os condutores, no caso específico do rafting, procuram utilizar estratégias que envolvem, por exemplo, a colocação de homens na parte dianteira do barco, por creditarem a eles maior força e melhor coordenação para remar. Com relação a este tema, Simões (2004) coloca que as mulheres começam a conquistar um espaço no cenário dos esportes de risco. Essas mulheres optam pela prática de um esporte de risco extremo, visto que, força, desafio, treinamento físico, vivência de riscos são atributos que possuem uma história na constituição do estereótipo masculino. Este mesmo autor prossegue seu pensamento concluindo que as mulheres desportistas "abrem mão da chamada passividade, ternura e obediência em troca de assertividade, agressividade e ambição, ou seja: de assumir um comportamento sui generis que incorpora quaisquer tipos de estereótipos sexuais" (Simões, p.28), procurando colocar seus limites pessoais em xeque.

Foram salientadas, ainda, as questões de relacionamento com familiares e namorados, no que tange ao ciúme do envolvimento da mulher com atividades em presença de outros homens, demonstrando-se, assim, certos tabus ainda vinculados à presença feminina nestas práticas, mesmo que as alterações sociais da modernidade sejam evidentes. Outro aspecto comentado foi o de que o preconceito era mais explícito especialmente quando as mulheres, de alguma forma, se saiam melhores do que os homens em alguma modalidade, com bom desempenho e performance.

Gradativamente, a mulher tem se inserido no contexto do esporte e, mais particularmente, do esporte de aventura na atualidade (Amaral \& Dias, 2008), o que faz com que as nove participantes do estudo possam expressar que não sentem qualquer tipo de precon- ceito advindo dos homens, em relação a estas práticas. Conforme salienta Breivik (2010), este aspecto pode representar um avanço nos valores, em que se percebem novas perspectivas de expressão de idéias e condutas referentes às questões de gênero frente aos ditames da pós-modernidade. Isto é diferente de tempos anteriores, em que se podia perceber com mais clareza os estigmas relativos à inserção da mulher no esporte de aventura. Entretanto, ainda restam algumas práticas que são tidas como masculinas. As variantes de esportes motorizados e mais tecnológicos, por exemplo, ainda são de domínio masculino, conforme Breivik (2010) salientou, entretanto, ele afirma que as mulheres se igualarão aos homens no futuro, tanto em nível de performance, quanto em número de praticantes.

Em alguns esportes na natureza, como o caso da citada corrida de aventura, a presença feminina é requisitada para compor uma equipe, sendo que esta norma faz parte da regra geral desta atividade. Esta particularidade faz com que a aceitação da mulher nesse esporte reforce algumas justificativas manifestadas pelas nove participantes do estudo, quando afirmaram que não vêem obstáculos quanto à aceitação por parte dos homens. Para elas, a presença feminina é aceita, porém, ao mesmo tempo, existe a cobrança de muita técnica e ações quase de igualdade com os homens, o que não deixa de ser desigual do mesmo modo e, inclusive, reforça a ideia de que a aceitação vem apenas por imposição de uma regra e não, necessariamente, pela mudança de valores.

Algumas vertentes das ciências têm discutido alguns aspectos dessa relação de gênero no campo do esporte e, mesmo com muita timidez, sobre a desigualdade entre gêneros nos esportes de aventura (Adelman, 2006). Porém, segundo Stoddart (2011), pouca atenção ainda é dada, nesses estudos, ao papel do ambiente definindo essas questões de gênero. Para esse autor, o ambiente é outro importante elemento que está presente na condição da ambiência, termo que 
representa a ligação entre o ser humano e o ambiente, em um processo dialético.

Sendo assim, para Stoddart (2011), deve-se levar em consideração nestas discussões, inclusive, o papel do ambiente de prática dos esportes, procurando compreender as maneiras como esse elemento é capaz de moldar as questões de gênero e as relações de poder, ali existentes, como é o caso da predominância masculina nos esportes motorizados e vividos em ambientes inóspitos, por exemplo. Essa reflexão poderia auxiliar a compreender melhor, tanto as desigualdades, quanto essa pseudo-igualdade aventada por algumas participantes do estudo, ao não sentirem diretamente o preconceito, mas afirmarem que são altamente cobradas em relação às suas performances, o que não deixa de representar certo preconceito.

No sentido de apresentar alguma sugestão para minimizar essas diferenciações de gênero incutidas nas sociedades e diminuir os estigmas de gênero ainda presentes em relação à mulher nos esportes, notadamente nos esportes de aventura, Hill (2010) evidencia a necessidade de revigorar estratégias de sensibilização, voltadas para a educação experiencial inclusiva. Esta autora aponta que, para se obter soluções inclusivas, torna-se necessário enfatizar a educação experiencial, por intermédio da qual se podem construir relações mais significativas e habilidades sociais menos preconceituosas. Este tipo de experiência diretamente na natureza revigora mais facilmente o senso de pertencimento, diminuindo ou atenuando sobremaneira, as possíveis mazelas em relação a preconceitos e estigmas.

Para Anthonissen (2011), a natureza selvagem, como cenário de diversas modalidades de esportes de aventura, tem sido tomada como um local em que se encontra presente a pressão ao conformismo de gênero, mas, também, segundo essa autora, pode favorecer oportunidades de reflexão sobre a perspectiva de alteração de valores estereotipados de gênero. Esta afirmação é baseada no facto de que a construção do domínio masculino nos esportes de aventura tem suas origens na grande presença e necessidade de características ditas masculinas, como autonomia, liderança, força física e decisão nestes esportes. Sendo assim, os estereótipos de gênero foram perpetuados, porém esta autora corrobora a sugestão de Hill (2010), anteriormente comentada, salientando que as experiências em ambientes naturais podem efetivamente favorecer novas tomadas de consciência e alteração de significados de gênero para a mulher participante.

Lugg (2003) amplia estas possibilidades de se buscar incentivo à alteração de valores por intermédio de atividades diretamente desenvolvidas em contato com o ambiente natural, por meio de excursões, já que estas permitem a vivência de experiências mais livres de valores incutidos culturalmente. Estas estratégias podem colaborar com a perspectiva de reflexão sobre novos encaminhamentos sobre o papel feminino no esporte de aventura.

Mesmo tendo essa ligeira vantagem numérica (duas participantes de diferença), a afirmação de que as mulheres deste estudo, inseridas nos esportes de aventura, não sofrem preconceito direto, não é tão convincente, uma vez que, em suas próprias justificativas, ficou patente o preconceito velado por parte dos homens, quando elas são cobradas em termos de performance, exigindo-se igualdade. Estas discrepâncias merecem outras pesquisas, capazes de fundamentar novos olhares sobre a temática de gênero nos esportes de aventura.

Foi indagado, na questão 03, se elas percebiam algum obstáculo em relação à aceitação da mulher nos esportes de aventura por parte dos homens. As respostas a esta questão evidenciam que, para 14 participantes, a aceitação por parte dos homens é boa, sendo que foi mencionado, inclusive, haver motivação, divisão de tarefas, ajuda e admiração para com as mulheres. Mesmo com esta positividade, essas participantes salientaram, porém, que os homens costumam cobrar mais das parti- 
cipantes do sexo feminino, em relação à força, velocidade, procurando igualá-las à performance masculina. Ainda para essas mulheres, o preconceito parece ter diminuído muito, quando se compara com tempos mais antigos.

As mulheres, para estarem presentes nas práticas dos esportes de aventura, sempre tiveram que extrapolar inúmeros obstáculos, especialmente aquelas consideradas pioneiras nessas atividades. Robertson (2003) evidenciou, em seu livro, que as primeiras mulheres que se envolveram com os esportes ditos radicais, enfrentavam restrições físicas e psíquicas, tendo em vista as inúmeras imposições ao papel feminino, desde o uso de vestimentas que não favoreciam qualquer tipo de prática esportiva, até mesmo, as pressões culturais e familiares. Entretanto, muitas delas quebraram esses códigos, para que pudessem vivenciar tais práticas. Ainda segundo o autor, uma das estratégias utilizadas pelas mulheres para conseguirem iniciar nos esportes de aventura era a união em clubes esportivos femininos, nos quais, uma dava apoio à outra nas empreitadas para superação dos estigmas vigentes.

Para Pfistera (2010), as diferenciações de gênero não podem ser consideradas naturais, uma vez que fazem parte de um construto - o de gênero, o qual é tido como socialmente construído. Sendo assim, para essa autora, essas diferenciações são também assimiladas e variam conforme as culturas, sendo bastante difíceis de serem superadas.

Mesmo com a grande maioria apontando haver uma boa aceitação por parte dos homens, duas participantes ainda sentem que não são efetivamente aceitas. As justificativas recaem no facto de alguns homens quererem competir com as mulheres para inferiorizá-las de algum modo, ou, com isto, desestimular a manutenção na prática. Estas condutas evidenciam a dificuldade ainda existente, de aceitação da presença feminina nesses esportes.

Para que a aceitação se faça de modo mais natural, Whittington (2006) revigora a idéia de que programas de atividades na natureza, que contemplem jovens adolescentes, podem oferecer oportunidades interessantes para a construção de novos valores de resistência aos estereótipos sociais já impregnados, revigorando novas noções de feminilidade, alterando aquelas mais convencionais. Também, segundo esse autor, pode-se promover o desenvolvimento de identidade de gênero positiva, durante a participação neste tipo de atividade ao ar livre. Estas atividades permitem que as mulheres possam explorar diferentes habilidades e facetas características de ambos os gêneros, o que levaria ao desenvolvimento de novos sentidos ao papel feminino.

Os resultados evidenciados nessa questão estão em desacordo com outros estudos (Gilenstam, Karp, \& Henriksson-Larsen, 2007; Pfistera, 2010), nos quais a rejeição feminina e as diferenças de gênero parecem ser mais presentes do que a aceitação, nos esportes de aventura. Esta afirmação, no entanto, deve ser relativizada, tendo em vista que esses autores focalizaram seu estudo em modalidade não considerada como de aventura, no caso, o hockey. Sendo assim, para Pohl, Borne, e Patterson (2000), existe uma lacuna de pesquisas que enfatizem a compreensão de como e por quê mudanças significativas se fazem dentro do contexto dos esportes de aventura, a ponto de concretizarem o que as mulheres participantes deste estudo evidenciaram como um degrau já alcançado, em relação à aceitação feminina nos esportes de aventura.

\section{CONCLUSÕES}

Considerando a contribuição das atletas na pesquisa exploratória e as reflexões advindas de diversos autores, nota-se que, conquanto a presença feminina nos esportes de aventura venha se disseminando, muitos entraves ainda se fazem presentes, tais como fatores financeiros que dificultam na aquisição de equipamentos específicos, restrita oportunidade de 
participação em eventos competitivos e deslocamento para locais de treino. Além disso, a falta de tempo para conciliar trabalho, família e o esporte também contribuem para dificultar o envolvimento das mulheres nas atividades de aventura.

Dentre outros fatores, destaca-se o preconceito de uma forma geral, o qual, mesmo sendo citado em baixa escala pelas participantes deste estudo, percebeu-se que existem diferentes tipos de preconceitos envolvidos, inclusive expresso de forma velada. Em relação à mulher, pode existir, por parte dos homens, o ciúme de estar em contato com outros homens, por visões estereotipadas da própria sociedade, ao se considerar um esporte estritamente masculino, ou pela desvalorização de capacidades e habilidades, como a força e resistência. Vale ressaltar que os fatores preconceituosos comentados neste estudo podem significar motivos de impedimento para que outras mulheres venham a praticar estas atividades. Apesar da maioria das atletas não se reportar a preconceitos e à não aceitação dos homens, ficou evidente que estes aparecem subliminarmente, merecendo atenção e aprofundamento em outras reflexões. Sugere-se que novos estudos possam ampliar essas e outras reflexões sobre a presença feminina nos esportes de aventura, para que se possa contribuir para a minimização dos aspectos discriminatórios, favorecendo discussões para se quebrar os tabus preconceituosos relacionados com as diferenças de gênero, bem como, para assegurar o aumento de oportunidade de participação de mulheres praticantes de atividades de aventura.

Agradecimentos:

Nada declarado.

Conflito de Interesses:

Nada declarado.

Financiamento:

Nada declarado.

\section{REFERÊNCIAS}

Adelman, M. (2006). Mulheres no esporte: Corporalidades e subjetividades. Movimento, 12(1), 11-29.

Amaral, A.V., \& Dias, C. A. G. (2008). Da praia para o mar: Motivos à adesão e à prática do surfe. Licere, 11(3), 1-22.

Anthonissen, L. (2011). An exploration of the gendered discourse in the talk of female facilitators of a wilderness programme (Master's Dissertation). University of Stellenbosch, South Africa.

Bahia, M. C., \& Sampaio, T. M. V. (2007). Lazer meio ambiente: Em busca das atitudes vivenciadas nos esportes de aventura. Revista Brasileira de Ciências do Esporte, 28(3), 173-189.

Betrán, J. (2003). Rumo a um novo conceito de ócio ativo e turismo na Espanha: As atividades físicas de aventura na natureza. In A. Marinho, \& H. T. Bruhns (Org.), Turismo, lazer e natureza (pp.157-202). Barueri: Manole.

Breivik, G. (2010). Trends in adventure sports in a post-modern society. Sport in Society: Cultures, Commerce, Media, Politics, 13(2), 260-273. doi10.1080/17430430903522970

Bruhns, H. T. (2009). A busca pela natureza: Turismo e aventura. Barueri: Manole.

Cheung, F. M., \& Halpern, D. F. (2010). Women at the top: powerful leaders define success as work + family in a culture of gender. American Psychologist, 65(3), 182-193. doi:10.10.1037/ a0017309

Costa, V. L. M. (2000). Esportes de aventura e risco na montanha. São Paulo: Manole.

Costa, V. L. M., \& Tubino, M. J. G. (1999). A aventura e o risco na prática de esportes vinculados à natureza. Motus Corporis, 6(2), 96-112.

Devide, F. P. (2003). História das mulheres na natação brasileira no século $X X$ : Das adequações às resistências sociais (Tese de Doutorado). Universidade Gama Filho,

Dias, C. A. G., \& Alves Jr., E. D. (Eds.). (2009). Em busca da aventura: Múltiplos olhares sobre esporte, lazer e natureza. Niterói: EdUEF.

Figueira, M. L. M. (2008). Skate para meninas: Modos de se fazer ver em um esporte em construção (Disser- 
tação de Mestrado). Universidade Federal do Rio Grande do Sul.

Gasques, M. V. (2002). Montanha em fúria: Aventura e drama no Cerro Aconcágua, o maior pico das Américas. São Paulo: Globo.

Gilenstam, K., Karp, S., \& Henriksson-Larsen, K. (2007). Gender in ice hockey: Women in a male territory. Scandinavian Journal of Medicine and Science in Sports, 18(2), 235-249. doi:10.1111/ j.1600-0838.2007.00665.x

Gill, D. L., \& Kamphoff, C. S. (2010). Gender in sport and exercise psychology. In J. C. Chrisler, \& D. R. McCreary (Eds.), Handbook of gender research in psychology (pp. 563-585). Springer Science: Business Media.

Goellner, S. V. (2003). Bela, maternal e feminina: Imagens da mulher na Revista Educação Física. Ijuí: Unijuí.

Goellner, S. V. (2005). Mulher e esporte no Brasil: Entre incentivos e interdições elas fazem história. Pensar a prática, 8(1), 85-100.

Gomes, O. C., \& Isayama, H. F. (2009). Corridas de aventura e lazer: Um percurso analítico para além das trilhas. Motriz, 15(1), 69-78.

Hill, L. D. (2010). Forging Inclusive Solutions: Experiential Earth Charter Education. Journal of Education for Sustainable Development, 4(2), 243-251. doi:10.1177/097340821000400212

Joly, M. C. R. A., \& Silveira, M. A. (2003). Avaliação preliminar do questionário de informática educacional (QIE) em formato eletrônico. Psicologia em estudo, 8(1), 85-92.

Lavoura, T. N., Schwartz, G. M., \& Machado, A. A. (2008). Aspectos emocionais da prática de atividades de aventura na natureza: A (re)educação dos sentidos. Revista Brasileira de Educação Física e Esporte, 22(2),119-127.

Lippa, R. A. (2010). Sex differences in personality traits and gender-related occupational preferences across 53 nations: Testing Evolutionary and Social-Environmental Theories. Archives of Sexual Behavior, 39(3), 619-636. doi:10.1007/ s10508-008-9380-7

Lugg, A. (2003). Women's experience of outdoor education: Still trying to be "one of the boys"?
In B. Humberstone, H. Brown, \& K. Richards (Eds.), Whose journey's? The outdoors and adventure as social and cultural phenomena (pp. 33-48). Penrith: The Institute for Outdoor Learning.

Marinho, A. (2008). Lazer, aventura e risco: Reflexões sobre atividades realizadas na natureza. Movimento, 14(2), 181-206.

Mourão, L. (1998). A representação social da mulher brasileira na atividade físico- desportiva: Da segregação à democratização (Tese de Doutorado). Universidade Gama Filho, Local

Oliveira, G., Cherem, E. H. L., \& Tubino, M. J. G. (2008). A inserção histórica da mulher no esporte. Revista Brasileira de Ciência e Movimento, 16(2), 117-125.

Ortiz, A. (2007). Na Estrada do Everest: trekking no Himalaia (2 ${ }^{\text {a }}$ ed.). Rio de Janeiro: Record.

Paixão, J. A. (2010). Esporte de aventura: Processo instrucional e situações de risco. Movimento $e$ Percepção, 11 (17), 90-100.

Pfistera, G. (2010). Women in sport - gender relations and future perspectives. Sport in Society: Cultures, Commerce, Media, Politics, 13(2), 234-248. doi:10.1080/17430430903522954

Pohl, S. L., Borne, W. T., \& Patterson, M. E. (2000). Women, wilderness and everyday life: A documentation of the connection between wilderness recreation and women's everyday lives. Journal of Leisure Research, 32 (4), 415-434.

Richardson, R. J. (1999). Pesquisa social: Métodos e técnicas. ( $3^{\mathrm{a}}$ ed.). São Paulo: Atlas.

Robertson, J. (2003). The magnificent mountain women: Adventures in the Colorado Rockies. ( $2^{\text {nd }}$ ed.). Lincoln: University of Nebraska Press.

Romariz, S. B., Devide, F. P, \& Votre, S. (2007). Atleta substantivo feminino: as mulheres brasileiras nos jogos olímpicos. Movimento, 13(1), 207-216.

Rutland, A., Killen, M., \& Abrams, D. (2010). A new social-cognitive developmental perspective on prejudice the interplay between morality and group identity. Perspectives on Psychological Science, 5(3), 279-291. doi:10.1177/1745691610369468

Saraiva, M. C. (2009). Por que investigar as questões de gênero no âmbito da educação física, esporte e lazer? Motrivivência, 12(19), 79-85. 
Schwartz, G. M. (2002). Emoção, aventura e risco: A dinâmica metafórica dos novos estilos. In M. S. Burgos, \& L. M. S. M. Pinto (Eds.). Lazer e estilo de vida (pp. 139-168). Santa Cruz do Sul: Edunisc.

Silva, P. P. C., \& Freitas, C. M. S. M. (2010). Emoções e riscos nas práticas na natureza: Uma revisão sistemática. Motriz, Rio Claro, 16(1), 221-230.

Simões, A. C. (2004). O universo das mulheres nas práticas sociais e esportivas. In A. C. SIMÕES, \& J. D. KNIJNIK (Org.). O mundo psicossocial da mulher no esporte: Comportamento, gênero, desempenho (pp. 23-46). Location: Publisher.

Stoddart, M. C. J. (2011). Constructing masculinized sportscapes: Skiing, gender and nature in British Columbia, Canada. International Review for the Sociology of Sport, 46(1), 108-124. doi:10.1177/1012690210373541
Tahara, A. K. (2004). Aderência às atividades físicas de aventura na natureza, no âmbito do lazer (Dissertação de Mestrado). Universidade Estadual Paulista, Rio Claro.

Tahara, A., Carnicelli Filho, S., \& Schwartz, G. (2006). Meio ambiente e atividades de aventura: Significados de participação. Motriz, 12(1), 59-64.

Valporto, O. (2006). Atleta, substantivo feminino: As mulheres brasileiras nos jogos olímpicos. Rio de Janeiro: Casa da Palavra.

Vertinsky, P. (2010). On being a feminist sport historian. Thirdspace: A journal of feminist theory $\mathcal{E}$ culture, 9(2), 1-9.

Whittington, A. (2006). Challenging girls' constructions of femininity in the outdoors. Journal of Experiental Education, 28(3), 205-221.

(c) EY-NC Todo o conteúdo da revista Motricidade está licenciado sob a Creative Commons, exceto quando especificado em contrário e nos conteúdos retirados de outras fontes bibliográficas. 